\title{
XXIV Jornades
}

de Foment de la Investigació

en Ciències Humanes i Socials

\section{IJI YNAVESSITAT}





\section{Fòrum de Recerca núm. 24}

Any 2019

XXIII Jornades

de Foment de la Investigació en Ciències Humanes i Socials
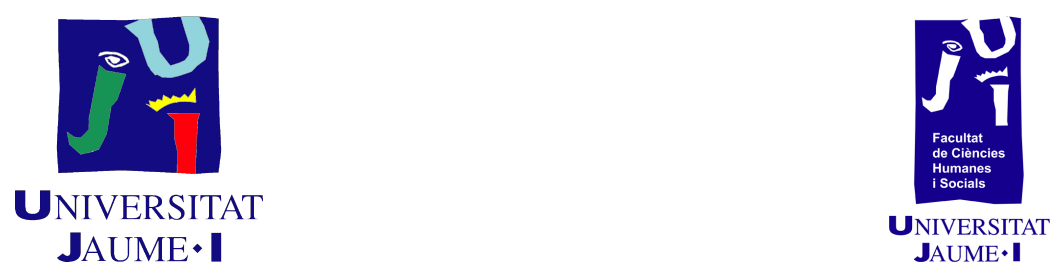
Fòrum de Recerca és una publicació destinada a divulgar els treballs presentats en les diferents edicions de les Jornades de Foment de la Investigació en Ciències Humanes i Socials.

\section{Direcció:}

Andreu Casero Ripollés

degà de la Facultat de Ciències Humanes i Socials

Universitat Jaume I

\section{Edició:}

Esther Monzó Nebot, Universitat Jaume I

\section{Comité Científic:}

Robert Arnau Roselló, María Carmen Campoy Cubillo, Hugo Doménech Fabregat, Carmen María Fernández Nadal, Jorge Martí Contreras, Susana Miquel Segarra, Patricia Salazar Campillo, Kim Schulte, Mónica Velando Casanova, Javier Vellón Lahoz, Esther Monzó Nebot

Aquest monogràfic ha rebut el suport de la Facultat de Ciències Humanes i Socials de la Universitat Jaume I.

(C) Del text: les autores i els autors, 2019

(C) De la present edició: Publicacions de la Universitat Jaume I, 2019

\footnotetext{
(c) (i) () Aquesta obra està subjecta a una llicència de Reconeixement-Compartirlgual 4.0 Internacional de Creative Commons.
}

ISSN: 1139-5486

DOI del número: http://dx.doi.org/10.6035/ForumRecerca.2019.24

DOI de la revista: http://dx.doi.org/10.6035/ForumRecerca 


\section{ÍNDEX}

Presentació. Les XXIV Jornades de Foment de la Investigació en Ciències Humanes i Socials. Andreu Casero Ripollés

\section{ESTUDIS DE GÈNERE}

Estereotipos de género, elección de estudios universitarios y práctica deportiva competitiva en una muestra de deportistas CADU de la Universitat Jaume I. Jahel Molina Ulldemolins, Carlos Hernando, Maria Escrig i M. Carmen Pastor

Ciudades diversas, urbanismo plural. (Re)pensando a Jane Jacobs.

David Luís López

Consecuencias diferenciales del trauma. Mikel García García

Degrowth from a feminist, transrational peace perspective.

Marisol Cristina Bock

\section{ESTUDIS DE TRADUCCIÓ I INTERPRETACIÓ}

Atención a las pacientes de origen chino en salud sexual y reproductiva en España: problemas de comunicación intercultural. María López Rubio

Formació i pràctica de la interpretació en contextos de crisi humanitària: un nou perfil professional. Maria Morales Chover

Una anàlisi crítica del discurs basada en els discursos de líders polítics de l'extrema dreta austríaca. Andrea Sanz Boscá

Problemes en la traducció de musicals: anàlisi de les estratègies per resoldre'ls. Joan Alfred Noll Obiol

La traducción al español de canciones de David Bowie: avance de resultados y conclusiones de un análisis descriptivo. Josep Barberá Ubeda

El doblaje de Shrek para el público infantil: análisis de las técnicas de traducción. Luz Belenguer Cortés

\section{ESTUDIS LITERARIS}

Maria Aurèlia Capmany: la masculinitat a debat. Sergio Trigueros 


\section{HUMANITATS I HISTÒRIA}

Globalización: Implementación y posibles alternativas. Erika

Tatiana Jiménez Aceros

Una lectura nietzscheana del budismo y una interpretación budista de Nietzsche. Yasmina Sabah Mellado Diaz

El adorno en estuco en la Valencia de 1700: proyecto de investigación.

Gaetano Giannotta 49

To be or not to be: Bridging diverging positions in the case of Charlie Hebdo. Irina Charlotte Ranalvosoa 51

Análisis, con perspectiva de género, del discurso propagandístico de la Segunda Guerra Mundial: uso del cuerpo humano. Elena Diana Nastasescu 53

La justicia transicional en perspectiva: los casos de Argentina, Colombia y Sudáfrica. Camilo Eduardo Espinosa Díaz 55

El torn pacífic de la Restauració al País Valencià: nous partits més enllà dels dinàstics. Javier Lara Fonfría 57 Isabel Clara Eugenia. La herencia interrumpida de la InfantaGobernadora. Gerardo Ferrer Bartoll 59

\section{EDUCACIÓ}

¿Y si Brandon Stark viviese en nuestro tiempo? Una aplicación del Diseño Universal del Aprendizaje en Educación Primaria para activar el rol del alumnado con parálisis cerebral. Raül Vlad Matei

Beneficis dels infants bilingües en l'adquisició de l'anglés com a tercera llengua. Irene Monzonís Carda 65

Acurtant distàncies, escoltant de prop. Paula Fabregat Mas 67

La orientación en contextos inclusivos: condicionantes, estrategias, recursos y roles. Erica Lorente Muñoz

La filosofía en el aula y la educación para la paz. Un enfoque de pensamiento crítico en la obra plástica El Guernica de Pablo Picasso. Ángel Miranda Torres

Un programa de intervención en psicología positiva para aumentar el bienestar de los docentes. María Luisa García Baldán 
Estudio demográfico y factores motivacionales de estudiantes con más de 25 años en universidades españolas. Yazmín

Perspectiva actual de la investigación en funciones ejecutivas y

el rendimiento académico. María Mónica Montes Miranda

Aplicación de las ciencias experimentales en nuestro entorno. La ruta científica como propuesta didáctica en alumnos de educación secundaria obligatoria. Mireia Adelantado-Renau i Gil Lorenzo Valentín

¿Es la inteligencia emocional en niños y adolescentes una cuestión de sexo? Martín Sánchez, Mireia Adelantado i Edgar Bresó

\section{ESTUDIS ANGLESOS}

The interpretation of spatial relations through a horizontal axis.

Nuria Flor Fabregat

Scandinavian influence in Old English poetry: A study of The Battle of Brunanburh. Lidón Prades Yerves

The effect of mediated learning experiences on the EFL oral proficiency. Ehsan Shahbazi Tochahi

The new millennial students and the 'multimodal' learning style:

Podcasting in the ESP classroom. Noelia Gargallo Camarillas 95

Young adult literature and EFL teaching: Sherman Alexie's The Absolutely

True Diary of a Part-time Indian (2007). Elena Dobre

\section{COMUNICACIÓ, PUBLICITAT I PERIODISME}

Más allá de las noticias falsas. Aproximación al fenómeno de la desinformación en línea en el contexto español. Laura Ros Martínez 101

Influence of celebrity endorsements on mature female cosmetic consumers. Leonor Alberola Amores 103

Comunicación de las marcas a través del storytelling. María José Gómez Aguilella 105

Fashion film: definición y tendencias. Gaspar Martín Molín 107

La cultura maker i la producció d'objectes de forma personal: nous horitzons per a l'ensenyament, aprenentatge i producció de l'art i el disseny. Vicent Juli Iborra Mondéjar 
La internacionalización del evento tradicional como potenciador de la marca territorio. El caso de las fiestas de la Magdalena de Castelló de la Plana. Paloma Teresa Aguilar Royo

Término influencer: sesgo entre investigación y estudios sectoriales.

Angela Agulleiro Prats

Propuesta metodológica para el análisis de la relación imagen-texto en el uso de Instagram como herramienta de comunicación política. 


\section{Presentació.}

Les XXIV Jornades de Foment de la Investigació en Ciències Humanes i Socials

Andreu Casero Ripollés 
El número 24 de Fòrum de Recerca recull els resums de les contribucions presentades a les XXIV Jornades de Foment de la Investigació en Ciències Humanes i Socials. Les Jornades, organitzades per l'editora d'aquest volum, Esther Monzó Nebot, vicedegana de la Facultat de Ciències Humanes i Socials de la Universitat Jaume I, van constituir un fòrum productiu de debat entre les investigadores i els investigadors novells $i$ experimentats del nostre centre. Les contribucions que ací es publiquen es van complementar amb conferències i tallers sobre els nous mitjans per a la recerca i la difusió dels resultats. En concret, el professor Borja Navarro Colorado, de la Universitat d'Alacant, va tractar el tema de les humanitats digitals, les possibilitats que obri i les oportunitats per formar-se i compartir inquietuds en fòrums especialitzats. Ramón Feenstra, professor de la nostra Facultat, va oferir una xarrada sobre la difusió dels resultats de la investigació i, gràcies a la col-laboració de la Biblioteca, Paloma Garrido i Lidia París van oferir un taller sobre la identitat digital de les persones investigadores.

L'any 2019, les publicacions derivades de les Jornades de Foment de la Investigació en Ciències Humanes i Socials presenten innovacions. En primer lloc, Fòrum de Recerca comença a presentar, just abans de les jornades els resums de les comunicacions, amb un procés d'edició que fa èmfasi en la redacció clara i rigorosa de les recerques que es presenten. En segon Iloc, s'introdueix un procés de selecció per a la publicació dels articles finals, amb l'ànim d'oferir a les investigadores i investigadors emergents un primer contacte amb els processos d'avaluació de la qualitat de les publicacions científiques. D'aquesta manera, s'intensifica la formació i la difusió que pretén la sèrie de jornades de foment de la investigació.

El número 24 de la revista Fòrum de Recerca s'estructura en set eixos diferents, que corresponen a les sessions on les autores i els autors van decidir presentar els seus estudis. Hi tenen una presència destacada les persones inscrites en els nostres programes de doctorat. El volum comença amb una secció sobre Estudis de Gènere amb articles que ens acosten propostes de gran rellevància social $i$ potencial d'impacte en l'àmbit de l'esport, l'urbanisme, la salut mental i els estudis de la pau. Tot seguit, els Estudis de Traducció i la Interpretació són un altre exemple de com les ciències humanes i socials ens ajuden a retribuir a les societats la seua inversió en ciència amb investigacions que busquen aportar solucions en l'àmbit de l'atenció a la salut, les crisis humanitàries i la comunicació política en un món de diversitat creixen. D'altra banda, els estudis sobre la traducció de cançons, els musicals i el cinema ens ofereixen aportacions en el marc de la circulació global de productes culturals. Tot seguit, els models de 
masculinitat centren l'atenció de la recerca inclosa en la secció d'Estudis Literaris. La secció d'Humanitats i Història ens acosta investigacions filosòfiques sobre els sistemes econòmics i morals, sobre la convivència de la diversitat, sobre la justícia transicional, a més d'altres estudis sobre el discurs propagandístic, el patrimoni artístic i polític valencians o reinterpretacions de processos històrics d'accés al poder i exclusió des de perspectives de gènere.

En l'àmbit de l'Educació, els projectes dedicats a potenciar la inclusió tenen una representació destacada, la qual cosa ofereix una diagnosi encertada de les necessitats actuals de la societat en matèria de diversitat funcional, de gènere i lingüística. També hi trobem l'estudi de les motivacions de l'estudiantat que, havent abandonat la ruta formativa, torna la mirada a la universitat per incrementar la seua formació. També és l'ànim de promoció de la convivència productiva el que trobem en experiències que ens acosten les aplicacions de l'art, les ciències experimentals o la psicologia per fomentar una visió crítica del nostre entorn. Estretament vinculada a aquesta secció, les recerques en l'àmbit dels Estudis Anglesos acaren l'expressió de relacions espacials des d'una perspectiva cognitiva, la influència de llengües escandinaves en l'anglés antic, la formació per a l'expressió oral, els nous estils d'aprenentatge en la societat digital o els usos de la literatura en l'ensenyament de l'anglés.

Finalment, una secció dedicada als estudis de Comunicació, Publicitat i Periodisme és testimoni del gran ventall d'interessos en aquests àmbits alhora que de la seua rellevància social. La secció recull recerques sobre els fenòmens de les notícies falses, dels influenciadors o dels fashion films, la publicitat adreçada a les dones, els usos de les narratives en la comunicació de marques, de la promoció de la marca territori, el canvi de paradigma en la producció de l'art i el disseny i els usos de les xarxes socials en la comunicació política.

Una vegada més, les XXIV Jornades de Foment de la Investigació en Ciències Humanes i Socials i el volum corresponent de Fòrum de Recerca són indicadors de la bona salut de la investigació del nostre centre, del potencial de les ciències humanes i socials per ajudar-nos a acarar les novetats socials i de l'esperit interdisciplinari que ens cal per fer justícia a la complexitat que ens envolta. Continuarem, pel camí marcat en aquests anys, cap a la vint-i-cinquena edició. 



\section{Estudis de Gènere}

Estudios de Género Gender Studies 



\section{Estereotipos de género, elección de estudios universitarios y práctica deportiva competitiva}

en una muestra de deportistas CADU de la Universitat Jaume I

Jahel Molina Ulldemolins jahel.molina@uji.es

Carlos Hernando Domingo hernando@uji.es

Maria Escrig Mateu al340190@uji.es

M. Carmen Pastor mpastor@uji.es 
Resumen

Actualmente las mujeres igualan o superan en número a los hombres que completan el nivel de educación superior, lo que sugiere una igualdad entre sexos. Sin embargo, siguen eligiendo titulaciones universitarias distintas, con una menor participación de mujeres en áreas académicas consideradas tradicionalmente masculinas. Los estereotipos de género también influyen en la práctica deportiva competitiva, y las mujeres que se identifican con rasgos más masculinos presentan una menor tasa de abandono. La influencia de estereotipos de género en el deporte y la elección de estudios universitarios se debe parcialmente a la internalización de la identidad de género, definida por las expectativas de la persona y del entorno sociocultural.

Nuestro estudio pretende explorar la relación entre estereotipos de género y elección de titulación universitaria en una muestra de 125 estudiantes de la UJI (61 mujeres), con una media de edad de 20 años, que competían en diferentes deportes de la liga universitaria. Se administró una batería de cuestionarios en formato de lápiz y papel, entre ellos la Escala de Estereotipos Actuales (EGA), y el Cuestionario de Datos Sociodemográficos. Los análisis preliminares sugieren una perpetuación del patrón tradicional de elección de titulación, con un desequilibrio entre sexos en todas las facultades, a excepción de la FCJE. Sin embargo, no se observaron diferencias significativas en las puntuaciones en el EGA, lo que no confirma la hipótesis de que los estudiantes que practican deporte de forma competitiva tendrían un perfil más masculinizado. Nuestros resultados sugieren que los estereotipos de género afectarían únicamente a las expectativas del entorno sociocultural para cada sexo, por influencia directa de los roles de género. Esto explicaría que hombres y mujeres sigan eligiendo estudios típicamente masculinos o femeninos, independientemente de que practiquen deporte de competición. Futuros estudios deberían incorporar un grupo de control equiparado en características sociodemográficas que no haya practicado deporte competitivo.

Palabras clave: estereotipos de género, práctica deportiva competitiva, elección de estudios universitarios, población universitaria. 


\section{Ciudades diversas, urbanismo plural. (Re)pensando a Jane Jacobs}

David Luís López dluis@uji.es 


\section{Resumen}

Jane Jacobs fue una de las más importantes y reconocidas voces del urbanismo feminista del siglo XX. Su mirada transgresora sobre el urbanismo se desarrolló en la Norteamérica de los años 50, caracterizada por el culto al crecimiento desmedido, las autopistas, los centros comerciales alejados de los centros de las ciudades y, con ello, el apogeo del vehículo privado. Todo ello hizo que Jacobs fuera ridiculizada por los urbanistas y tecnócratas, que jamás la tuvieron en cuenta. Hoy, casi 60 años después de su publicación más relevante y más de una década después de su muerte, su legado cobra fuerza. Apenas quedan voces que nieguen que las intervenciones en la ciudad deban hacerse desde el conocimiento de la sociedad y sus necesidades concretas. La calle deviene, para Jacobs, el epicentro del espacio público, de un lugar compartido en el que habitamos todas y todos y debe ser integrador para, así, construir ciudades plurales, abiertas, solidarias y participativas. Esta contribución aporta una visión crítica de ese legado desde la perspectiva actual.

Palabras clave: género, feminismos, historia, urbanismo, diseño, arte, arquitectura, activismo. 


\section{Consecuencias diferenciales del trauma}

en los géneros

Mikel García García

al368001@uji.es 
Resumen

Los eventos adversos vividos en el desarrollo ontológico impactan en función de la capacidad que tienen los sujetos de afrontarlos. Hay evidencia científica de que, cuando más tempranos y repetidos sucedan, más probable es que sean traumáticos, sobre todo si son persistentes y acumulados. La traumatización es una consecuencia de la violencia estructural de las sociedades y es mayor en las patriarcales. En esta comunicación se presenta un estudio de campo sobre traumatización, realizado como tesis para un doctorado en Paz, Conflictos y Desarrollo. La muestra son 652 sujetos de España y Colombia. El 81,4\% de la muestra es consciente de haber experimentado trauma. Las mujeres experimentan significativamente más maltrato, tanto en la infancia, como de pareja, y más abusos sexuales, mientras que los hombres experimentan significativamente más violencia social, grupal y escolar. El 6,9\% de las mujeres y el $2,2 \%$ de los hombres manifiestan la relación con pareja maltratadora como un evento vital negativo en su experiencia. Las mujeres experimentan más eventos traumatógenos desde la infancia temprana, y en todas las etapas del desarrollo. Resultan más traumatizadas que los hombres, con una sensación subjetiva de haber recibido maltrato histórico, de pareja y obstétrico. Como consecuencia tienen más miedo a la muerte, una moralidad más deontológica, apegos más inseguros y evitantes, y dificultad para colaborar en la resolución de conflictos. La motivación ética es diferente en la cosmovisión de hombres y mujeres. En la comunicación se discute sobre los efectos de los mitos y complejos culturales en la aculturación de las mujeres. También se proponen acciones a realizar para modificar esta situación.

Palabras clave: trauma, ética, patriarcado, complejos culturales. 


\section{Degrowth from a feminist,}

transrational peace perspective

Marisol Cristina Bock

al295846@uji.es 
Abstract

We are facing multiple global interlocking crises in the economic, ecological and social realms. Sustainable economic degrowth recognizes the hegemonic economic growth paradigm as a key problem. As a solution it aims to promote a just downscaling of the economy, from interdisciplinary perspectives. While equality is a crucial component for degrowth advocates, the movement lacks an engagement with feminist theory. This work seeks to identify how feminism might enhance and promote the degrowth movement.

The present study provides theoretical examination of the overlapping fields of degrowth and feminism as well as related areas, from a peace perspective by engaging in conceptual analysis, deconstruction and critical thinking. The peace perspective includes a notion of epistemological shift coined by Martínez Guzmán (2001) and links with transrational peace research by Dietrich (2016). The results of the analysis show that capitalism is dependent on economic growth, yielding patriarchal features. Feminism, which promotes the abolishment of patriarchy is a plural, heterogeneous movement whereby the pursuit and promotion of individual choices prevails, turning the overall canon of feminism into a neo-liberal market of ideas within the growth paradigm. I propose that a feminism useful for the degrowth context should 1) pursue gender equality, 2) recognize the deeplying cultural roots of patriarchal violence, 3) consider intersectionality 4) have an awareness of the parallels between oppression of women and oppression of nature.

From a transrational peace perspective, a parallel between patriarchal features in the economic logic based on scarcity and the oppression of women can be seen, considering the significance of feminine and masculine principles as described by adjacent fields of study. In conclusion, degrowth may be enhanced and promoted by adopting a growth-critical ecofeminist, transrational perspective. Open research lines include testing the applicability of such insights in the practical realm.

Keywords: degrowth, feminism, transrational, peace. 


\section{Estudis de Traducció i Interpretació}

Estudios de Traducción e Interpretación Translation and Interpreting Studies 



\section{Atención a las pacientes de origen chino en salud sexual y reproductiva en España:}

problemas de comunicación intercultural

María López Rubio

al287956@uji.es 


\section{Resumen}

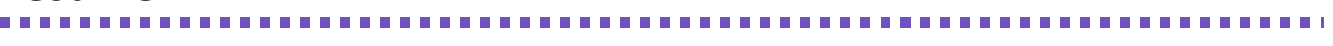

Como consecuencia del flujo de inmigración que España ha experimentado desde finales del siglo $\mathrm{XX}$, se ha producido un importante incremento en el número de nacimientos de niños y niñas cuyas madres son de origen extranjero. No obstante, este auge no ha venido acompañado de mejoras para conseguir que se respeten los derechos de las personas usuarias, independientemente de su procedencia, en los servicios sanitarios. A pesar de tener las mismas obligaciones que las mujeres autóctonas, las mujeres de origen extranjero que esperan ser madres en España se encuentran con grandes limitaciones a la hora de ejercer sus derechos en ese campo. Mediante el presente trabajo de investigación, se pretende mostrar algunos de los problemas interculturales que se producen en la interacción médico-paciente en los centros de salud y hospitales públicos de la Comunidad Valenciana. A partir de los datos obtenidos de las entrevistas y los grupos de discusión con miembros del personal sociosanitario y pacientes de origen chino, se busca descubrir qué problemas de comunicación intercultural inciden más notablemente en la atención que reciben las pacientes de origen chino en el ámbito de la salud sexual y reproductiva y cómo podría mejorarse la situación en este sector. El resultado del análisis ha puesto de manifiesto que la visión de las pacientes de origen chino y de los miembros del personal sociosanitario español en cuanto a la atención en salud sexual y reproductiva es muy distinta, ya que son los miembros del personal sociosanitario quienes más problemas encuentran en este ámbito, especialmente problemas de cultura en general, problemas relacionados con los patrones de interacción comunicativa, problemas de comunicación lingüística y problemas administrativos-laborales.

Palabras clave: chino, pacientes, problemas de comunicación, patrones de interacción comunicativa, salud sexual y reproductiva. 


\section{Formació i pràctica de la interpretació en contextos de crisi humanitària:}


Resum

La crisi del Mediterrani és la crisi migratòria i humanitària més greu d'Europa des de la Segona Guerra Mundial. Dins l'àmbit nacional, això ha provocat un augment en el nombre de demandants d'asil i de persones amb necessitats humanitàries que requereixen una mediació comunicativa per obtenir protecció internacional i per satisfer les seues necessitats més bàsiques. Atés el caràcter sobtat en l'increment de la demanda, les organitzacions d'ajuda humanitària no han tingut el temps ni els recursos necessaris per proveir-se de professionals que puguen complir les necessitats concretes de la interacció entre el personal que ha de decidir quines vies administratives i jurídiques són pertinents per vehicular l'ajuda requerida $\mathrm{i}$ les persones que es troben en una situació culturalment desconeguda, sense capital lingüístic $i$ en una situació extrema des de punts de vista socials, administratius, econòmics, polítics i, fins i tot, personals.

Aquesta contribució, a partir d'una observació retrospectiva, directa i participativa al Departament d'Asil de la Creu Roja Provincial de València, visibilitzarà els requeriments de comunicació i cooperació de les interaccions esmentades $\mathrm{i}$ analitzarà quin perfil o perfils existents tenen la capacitat de cobrir-los. A partir d'aquest estudi de cas, es detecten buits, solapaments $\mathrm{i}$ interaccions dels perfils existents que suposen problemes de cooperació entre el personal i els usuaris de Creu Roja. Amb la perspectiva de millorar la situació comunicativa descrita, on persones al-lòfones requereixen atenció humanitària i interaccionen amb organitzacions especialitzades, es proposa una reconsideració dels límits epistemològics de la interpretació en situacions de crisi humanitària per incloure-hi tasques ara reservades a la mediació.

Paraules clau: comunicació intercultural; cooperació; crisi migratòria; interpretació; mediació; organitzacions humanitàries. 


\section{Una anàlisi crítica del discurs basada en els discursos de líders polítics de l'extrema dreta austríaca}

a partir de l'obra de teatre polític Alles kann passieren!, de Doron Rabinovici i Florian Klenk 
Resum

Aquest treball analitza el discurs polític de l'extrema dreta austríaca a partir de l'obra de teatre polític Alles kann passieren!, de Doron Rabinovici i Florian Klenk, amb l'objectiu d'evidenciar els recursos lingüístics amb què els membres de I'FPÖ (Freiheitliche Partei Österreich) Herbert Kickl, HeinzChristian Strache i Norbert Hofer propaguen la seva ideologia.

El treball se centra en el context d'auge de l'extrema dreta arreu d'Europa i la legitimació d'un discurs populista estigmatitzador de rebuig als immigrants i les minories. El corpus utilitzat és oral i monolingüe, i està compost per un mosaic de discursos seleccionats per Doron Rabinovici i Florian Klenk com a representants de la ideologia populista d'exclusió. Per tal d'acarar l'objecte d'estudi des d'un punt de vista crític i empíric, duré a terme una anàlisi lingüística descriptiva amb el model de l'Anàlisi Crítica del Discurs de Norman Fairclough, el qual permet visibilitzar la relació entre llengua i societat a través d'elements d'anàlisi lingüística, com també la relació entre la pròpia anàlisi i les pràctiques analitzades. Estudiaré els processos i els participants de les accions que componen els discursos i, a partir de l'esquema de Fairclough, contestaré les preguntes gramaticals del model, relacionades amb els valors experiencials i relacionals. Aquesta tasca em permetrà extreure conclusions sobre el rerefons ideològic que presenta aquest tipus de pràctica discursiva en el context espai-temporal en què se situa el material d'anàlisi, establir estratègies que es repeteixen en les intervencions i fer que aspectes opacs, com les relacions de poder $\mathrm{i}$ de dominació, es tornin més transparents.

Paraules clau: Anàlisi Crítica del Discurs, ideologia, discurs polític, relacions de poder, pràctiques discursives. 


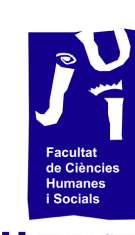

UNIVERSITAT

\section{Problemes en la traducció de musicals:}

anàlisi de les estratègies per resoldre'ls

Joan Alfred Noll Obiol

al367994@uji.es 
Resum

Durant la realització de la meva tesi de màster, que inclou una traducció i comentari de Sunday in the Park with George (Sondheim/Lapine), van sorgir diversos problemes en la traducció per a escena de musicals, així com estratègies possibles per resoldre'ls. Aquests resultats ofereixen una base coherent per a la meva recerca següent, que inclou la comparació de diferents traduccions de musicals i la revisió d'aquests resultats mitjançant la implementació d'entrevistes semi-estructurades per als traductors experts que realitzen una tasca tan restringida (Apter, 1985).

El musical, un gènere popular a Espanya en versió traduïda (Mateo, 2008), s'estudia des d'un marc teòric que inclou la traducció funcional (Nord, 2006), la traducció de texts lligats a música (Golomb, 2005) i l'Aproximació Pentatló a la traducció cantable (Low, 2012). La metodologia que aplico inclou una anàlisi estructural dels texts, la comparació entre traduccions i la realització d'entrevistes per triangular els resultats inicials. El material analitzat inclou dues traduccions del musical Into the Woods (Sondheim/Lapine) al català i a l'italià. Els resultats inicials de l'anàlisi textual, que té en compte les normes aplicades (Toury, 1995), suggereixen una diferenciació estilística entre traduccions, amb un to més humorístic en català.

En conclusió, la traducció de musicals per a l'escena inclou diverses restriccions difícils d'equilibrar, dominades per la dependència amb la música i analitzables comparant diverses traduccions. Aquest procés d'anàlisi permet revisar la intervenció del traductor(a) en forma d'idees afegides o un estil diferent en el text meta. Les entrevistes dissenyades han de permetre oferir major comprensió del procés i les seves particularitats, així com consolidar els resultats obtinguts.

Paraules clau: musicals, problemes de traducció, traducció relacionada amb la música, Sondheim, entrevistes semi-estructurades. 
Apter, Ronnie. 1985. «A Peculiar Burden: Some Technical Problems of Translating Opera for Performance in English». Meta: journal des traducteurs / Meta: Translators' Journal 30 (4): 309-319.

Golomb, Harai. 2005. «Music-linked Translation (MLT) and Mozart's Operas: Theoretical, Textual and Practical Perspectives». A Song and Significance: Virtues and Vices of Vocal Translation, editat per Dinda L. Gorlée, 121-162. Àmsterdam: Rodopi.

Low, Peter. 2012. «Purposeful translating: the case of Britten's vocal music». A Music, text and translation, editat per Helen Julia Minors, 69-79. Londres: Bloomsbury.

Mateo, Marta. 2008. «Anglo-American Musicals in Spanish Theatres». The Translator 14 (2): 319-342.

Nord, Christiane. 2006. «Translating as a purposeful activity: a prospective approach». Teflin Journal 17 (2): 131-143.

Toury, Gideon. 1995. Descriptive Translation Studies and Beyond. Àmsterdam i Filadelfia: John Benjamins. 



\section{La traducción al español de canciones de David Bowie:}

avance de resultados y conclusiones de un análisis descriptivo

Josep Barberá Ubeda al365369@uji.es 
Resumen

En la ponencia propuesta, se presenta un avance del resultado del análisis descriptivo efectuado en la tesis doctoral "Opciones funcionales y soluciones técnicas en la traducción de canciones del inglés al español: el caso de David Bowie», con un corpus de 14 versiones en español de 11 canciones del autor, originalmente compuestas en inglés.

Como antecedentes, se citan: la aproximación holística basada en los niveles estratégico, traductológico y técnico (descrita en el artículo "Decision-making in Song Translation: An Approach to the Spanish Translation of David Bowie's Song 'Space Oddity'», revista Trans); la centralidad del análisis de la canción original en cuanto a estilo, estructura estrófica o compleja, enfoque logo o músico-céntrico, valores expresivos, patrones (presentada en las XXIII Jornades de Foment de la Investigació); la reagrupación y categorización de los resultados del análisis (presentada en el 37 Congreso Internacional de AESLA-Universidad de Valladolid); la validación de la metodología y la reformulación de algunos principios (Low, Cotes Ramal) aplicables a la traducción de canciones populares (presentado en el XVI Congreso Internacional Traducción, Texto e Interferencias, Universidad de Córdoba, a celebrar en Murcia).

Para concluir la presente propuesta, se avanzan algunas conclusiones generales de la investigación objeto de la tesis, en los ámbitos teórico y práctico, al respecto de la traducción de canciones pop-rock en general. Con carácter no exhaustivo, se adelantan: la viabilidad de las traducciones cantables, minimizando el sesgo hacia la adaptación; la relativa flexibilidad del ritmo musical, o la importancia de la pericia del traductor en la reducción de las casi inevitables concesiones en el ámbito de la expresividad estilística, crucial en la obra del autor, agravadas por las diferencias fónicas y métricas entre ambas lenguas.

Palabras clave: Traducción cantable, métrica poética, ritmo musical, adaptación, David Bowie. 


\title{
El doblaje de Shrek para el público infantil:
}

\author{
análisis de las técnicas de traducción
}

Luz Belenguer Cortés

luzbelenguercortes@gmail.com 
Resumen

El doblaje busca la verosimilitud, la naturalidad del lenguaje oral a la vez que reflejar el contenido del texto origen. No obstante, en la traducción de productos infantiles, entra en juego otro condicionante: el receptor. Determinadas soluciones pueden estar determinadas por la necesidad de garantizar la comprensión del producto audiovisual o por la voluntad de acercamiento al receptor potencial, lo que conduce a prácticas que han sido catalogadas como intervencionistas; nuestra hipótesis es determinar si este era el caso en el doblaje de la saga fílmica Shrek.

Mi TFG consistió en un estudio descriptivo de la traducción al español de la película Shrek (2001). Para llevar a cabo el análisis, se propuso una clasificación de técnicas de traducción que suponía un avance respecto a propuestas anteriores. El desarrollo del estudio arrojó un total de 400 muestras, las cuales se etiquetaron siguiendo la clasificación propuesta. Y, tras el estudio de los patrones observados, pudimos concluir que la comprensión del público infantil primaba a la hora de elegir las técnicas de traducción, de modo que la centralidad del receptor condicionaba el uso de técnicas no literales en la traducción española.

Como perspectivas de futuro me planteo: analizar toda la saga, entrevistar al equipo de doblaje, llevar a cabo un estudio experimental en el receptor, realizar un experimento en el público adulto e infantil y determinar cómo se podría evaluar la aceptabilidad en este último.

Palabras clave: doblaje; producto audiovisual para niños; literatura infantil y juvenil, domesticación. 


\section{Estudis Literaris}

Estudios Literarios Literature Studies 



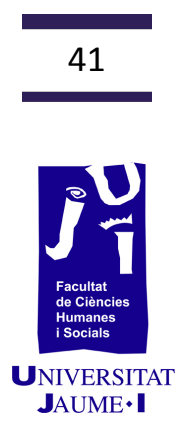

\title{
Maria Aurèlia Capmany:
}

\author{
la masculinitat a debat
}

Sergio Trigueros Navarro

navarros@uji.es 
Resum

Maria Aurèlia Capmany i Farnés (1918-1991) és una de les veus més importants de la literatura femenina en català. De la seua obra, en destaca la varietat de gèneres i la seua capacitat d'adaptar-se al canvi dels temps. Des de la novel·la existencialista fins a la policíaca, l'escriptora mostra una gran solvència a I'hora d'imaginar nous mons. Uns mons que, per una altra banda, passen pel sedàs de la seua experiència i la seua ideologia, vertebrada en tres branques: la catalanitat, el feminisme i la militància en l'esquerra.

L'objectiu d'aquesta recerca consisteix en una anàlisi dels personatges masculins d'obres com Betúlia, Feliçment sóc un dona o El jaqué de la democràcia. El marc teòric en què s'insereix aquest estudi es troba vinculat amb les diverses línies de pensament que convergeixen en l'hermenèutica de la integració. L'objectiu principal és identificar els estereotips masculins que l'autora recrea en les seues narracions. La possible identificació d'aquests és un procés complex que abasta diferents mecanismes, des dels més visibles, com els recursos descriptius de la prosopografia i l'etopeia, fins d'altres que es troben lligats amb la perspectiva de la recepció, l'implícit i la inferència, especialment el discurs atribuït a aquests personatges.

L'estudi tracta de valorar la funció del discurs en la creació dels personatges. Acceptant el concepte bakhtinià de polifonia, veurem com el lector identifica i perfila les coordenades ideològiques dels personatges a través d'un discurs social reconeixible en un marc cognitiu. Fruit d'aquest treball de reconeixement per part del lector considerem possible parlar d'uns estereotips que es repeteixen al llarg de l'obra de Maria Aurèlia Capmany i que alhora ens serveixen tant per a fer un retrat de la societat de l'època com per conéixer el posicionament de l'autora respecte de determinats comportaments o elements doxals.

Paraules clau: discurs, estereotip, feminisme, ideologia, narrativa. 


\section{Humanitats i Història}

Humanidades e Historia Humanities and History 



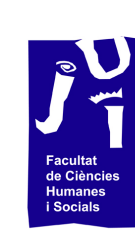

UNIVERSITAT JAUME・I

\section{Globalización:}

\section{Implementación y posibles alternativas}

Erika Tatiana Jiménez Aceros

al368001@uji.es 


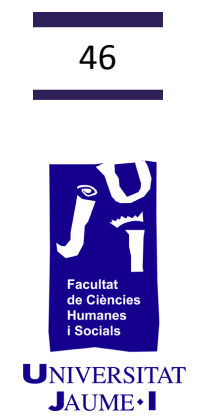

\section{Resumen}

La palabra globalización es recurrente y se relaciona con conceptos como capitalismo, explotación, pobreza, abrir mercados o extractivismo. Efectivamente, la globalización emerge de una necesidad capitalista por conectar territorios para dar acceso a la exportación e importación de mercancías o materias primas, indispensables para aumentar el capital económico de las industrias y los países capitalistas y así obtener el poder económico tan anhelado de manera global. Se entablan asimismo relaciones políticas y sociales que facilitan la compra y venta de empresas entre países. Con la globalización, somos una sociedad más comunicada, pero no mejor informada.

El objetivo de esta contribución es visibilizar las propuestas alternativas a la globalización silenciadas en el discurso dominante. Las preguntas de investigación son: ¿Podemos hablar de paz en tiempos de la globalización? ¿Quiénes hablan en contra de la globalización? ¿Existen alternativas vigentes para contrarrestar el fenómeno de la globalización? Para dar respuesta a esas preguntas aclararemos qué se entiende por globalización y cómo se puso en marcha en sociedades consumistas. Se tratarán las perspectivas diferentes a la globalización contenidas en el libro Voces en contra de la globalización de Carlos Taibo y Carlos Estévez, quienes, en un compendio de entrevistas, conversan con expertos sobre el tema y exponen las razones por las cuales la globalización es un fenómeno hegemónico. En tercer lugar se apuntarán alternativas que pueden sustituir a la globalización o darle un equilibrio, según apunta Christian Ferber en su propuesta de economía para el bien común.

Palabras clave: globalización, consumo, capitalismo, decrecimiento, economía del bien común. 


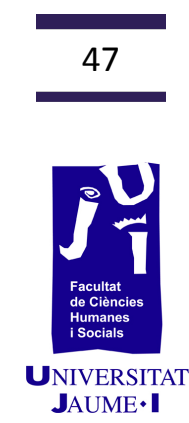

\section{Una lectura nietzscheana del budismo}

y una interpretación budista de Nietzsche

Yasmina Sabah Mellado Diaz

al338928@uji.es 
Resumen

La interpretación de Nietzsche sobre el budismo cuestiona la forma de entender diferentes conceptos de la perspectiva budista, a la cual categoriza de religión nihilista debido a la búsqueda de liberación del sufrimiento mediante la compasión. La indagación de determinadas ideas de ambos pensamientos posibilita encontrar sus diferencias y sus semejanzas para conducirlos hasta un punto común. Se analizan comparativamente una serie de conceptos como Superhombre y Nirvana, así como eterno retorno y samsāra empleando un fragmento de una de las destacadas obras de Nietzsche y una recopilación bibliográfica de diversas fuentes que estudian las dos visiones. Este estudio se encamina hacia la reflexión de la relación entre los elementos que componen las dos filosofías a partir de las críticas que proporcionan estudiosos tanto de las filosofías orientales como de las occidentales.

Se concluye que el pensamiento nietzscheano y el budismo comparten el propósito de vivir el momento presente gracias a la transmutación de los valores y la liberación del sufrimiento. Al mismo tiempo, se distancian en aspectos concretos que se inspeccionan con la equiparación de los términos mencionados previamente. El contraste de esas concepciones se asocia a la contemplación del dolor como fuente de placer en Nietzsche y de aceptación en el budismo, cuyo fin es la felicidad y la plenitud del ser humano. El aporte fundamental de ambos enfoques no renuncia a una forma de vida basada en la aceptación de uno mismo, donde prima el vitalismo nietzscheano o la paz interior del budismo. El aspecto definitivo que se vuelve a remarcar es el estado que se alcanza por medio de las propuestas nietzscheanas y de las enseñanzas budistas enfocándose en el aquí y el ahora.

Palabras clave: budismo, religión nihilista, liberación del sufrimiento, compasión, Superhombre, Nirvana, eterno retorno y samsāra. 


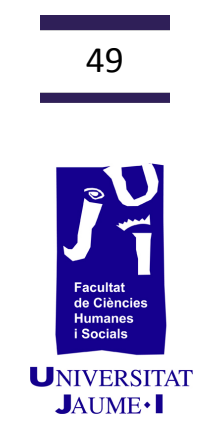

\section{El adorno en estuco en la Valencia de 1700:}

proyecto de investigación 
Resumen

Mi proyecto de tesis doctoral pretende profundizar en el conocimiento de la profesión y práctica de la ornamentación en estuco en la València del siglo XVIII. Se trata de un tema que ha sido siempre abordado de manera indirecta por parte de estudiosos de la arquitectura que sometieron el estudio del adorno al análisis de los proyectos, materiales y artistas más destacados de la propia arquitectura. A partir del estado de la cuestión planteado, pretendo lograr la independencia de los estudios sobre los adornos en estuco: 1) analizando la producción decorativa tanto de los artistas más destacados como de los considerados menores hasta la fecha; 2) profundizando en los modelos estilísticos e iconográficos que manejaron, dando importancia tanto a los antecedentes locales como a los europeos, para lo que se estudiará de manera comparada la realidad valenciana con la de Sicilia en la que la actividad de los estucadores experimentó un desarrollo similar; 3) estudiando la relación entre los adornistas y las instituciones de control de las artes como los gremios y la academia, respecto a las cuales lograron, en ocasiones, una gran independencia. Este proyecto, además de aquilatar las biografías de artistas como Francisco, Manuel e Ignacio Vergara, José Artigues o Luis Domingo, consentirá determinar las causas del formidable desarrollo del adorno y de la profesión del ornamentista en la València del siglo XVIII, explicar sus fases y fuentes estilísticas y acotar los motivos de su progresiva disolución a partir del arraigo del academicismo ilustrado.

Palabras clave: adorno, arquitectura, estuco, siglo XVIII, València. 


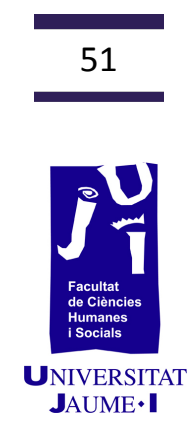

\section{To be or not to be:}

Bridging diverging positions in the case of Charlie Hebdo

Irina Charlotte Ranalvosoa

cha.ranaivosoa@live.fr 
Abstract

In the aftermath of the 7th January 2015 attacks, when jihadist gun killed 12 people at the headquarters of the satirical magazine Charlie Hebdo in Paris, the slogan Je suis Charlie ('I am Charlie') quickly spread on media platforms in support of the magazine and the victims. However, few -if not many- people did not support the -entire- slogan and would even claim Je ne suis pas Charlie ('I am not Charlie'). Such diverging points of view often led to heated debate -if not arguments- on social media or long discussions between friends. Finding common grounds between these two sides has to be thoroughly scrutinized yet with a view to reaching reconciliation points and, finally, resolving if not positively transforming such conflict. The conflict finds its roots in satire -the controversial tool used by Charlie Hebdo in its weekly issues- and the long-sustained imbalance of power between different cultures residing in France. The right to freedom of expression and the value of laïcité have been claimed so far in support of the newspaper in France. Although such views barely find support around the world, no solution has been suggested yet with a view to finding reconciliation. This contribution will apply approaches taken from peace studies to bridge the diverging positions emanating from apparently- conflicting identities. Indeed, the need for dialogue and cultural diversity ought to be promoted through education and communication to lower the affective filter that hampers mutual understanding.

Keywords: Charlie Hebdo, dialogue, identity. 


\section{Análisis, con perspectiva de género, del discurso propagandístico de la Segunda Guerra Mundial:}

uso del cuerpo humano 


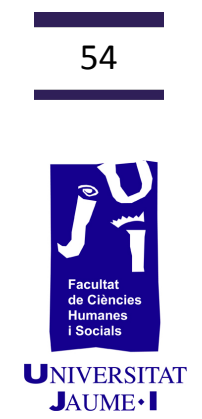

\section{Resumen}

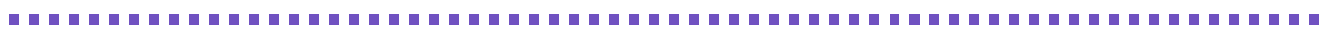

«La propaganda trata de imponer una doctrina a todo el pueblo [...] La propaganda orienta a la opinión pública en el sentido de una determinada idea y la prepara para la hora del triunfo» (Adolf Hitler, Mein Kampf, 1926). El siglo xx fue llamado la era de los extremos por el historiador Eric J. Hobsbawm. Y, en efecto, ha estado marcado por dos guerras mundiales, por las peores dictaduras de la historia y por una tremenda crisis económica. Durante la Segunda Guerra Mundial, la propaganda se intensificó hasta, quizás, su punto más álgido, puesto que, mientras los Aliados y el Eje se preparaban para la guerra, era necesario que ambos motivaran y aumentaran la población. Las técnicas utilizadas tenían como meta mantener la confianza de las tropas en sí mismas e intimidar a las fuerzas de la oposición. El objetivo principal de la investigación es analizar la situación en el periodo de entreguerras, con énfasis en los carteles de propaganda de esos años. Más concretamente se examinará la imagen que cada uno de los bandos tenía sobre el rol de los hombres y las mujeres en la sociedad. Es de especial interés observar la estrategia de guerra escogida por cada uno de los bandos, pero, todavía lo son más las características sociales representadas en la propaganda, ya que describen la organización de los estados y el valor que concedían a sus ciudadanos. La metodología utilizada para los fines de la presente investigación es la revisión de la literatura existente al respecto, utilizando Hellenic Academic Libraries Link (HEAL-LINK), y el análisis de la propaganda.

Palabras clave: discurso propagandístico, perspectiva de género, Segunda Guerra Mundial, cuerpo humano. 


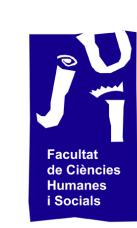

UNIVERSITAT JAUME・I

\title{
La justicia transicional en perspectiva:
}

\author{
los casos de Argentina, Colombia y Sudáfrica
}

Camilo Eduardo Espinosa Díaz

camiloespinosa10@gmail.com 


\section{Resumen}

El presente artículo aborda el dilema entre justicia y verdad, una paradoja presente en los juicios más importantes de la historia reciente de la humanidad (Núremberg, Tokio y los tribunales ad hoc en la ex Yugoslavia y Ruanda). La pregunta de investigación es, teniendo en cuenta el acuerdo de paz de 2016 entre el Estado colombiano y el grupo guerrillero Farc, qué puede aprender este país de la experiencia de los Juicios a las Juntas Militares en Argentina y de la Comisión de la Verdad y la Reconciliación en Sudáfrica, en relación con los conceptos de justicia y verdad. La experiencia en Colombia mostró un camino intermedio, en el que se tomaron medidas importantes de Sudáfrica, como darles voz a las víctimas; y de Argentina, con la administración de justicia para todos los actores, incluidos terceros, que participaron en el conflicto armado.

Palabras clave: justicia transicional, verdad, paz, conflicto armado, Colombia. 


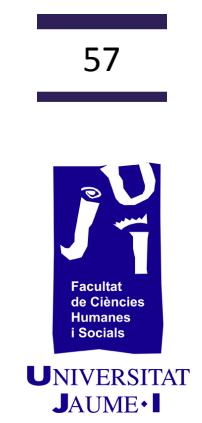

\section{El torn pacífic de la Restauració al País Valencià:}

nous partits més enllà dels dinàstics

Javier Lara Fonfría

al259489@uji.es 
Resum

Alçat irreverentment l'exèrcit contra el legítim govern de la nació, Espanya restà dividida en dues, una Espanya governada pels sublevats i una Espanya en què la legalitat republicana lluitava per refermar-se i mantenir-se en el poder. En aquest context, València, de costum cap i casal de les seus comarcals tradicionals, des del Baix Maestrat fins al Baix Segura, veia ara recaure sobre ella la capitalitat de tot l'Estat espanyol.

Assetjat Madrid, i amb la capital a Llevant, València començà a ser vista com el refugi que tothom desitjava i anhel-lava, ja que la ciutat, des de la seua posició de rereguarda, no havia conegut encara les bombes i, en certa manera, la vida quotidiana continuà igual durant els primers mesos de la guerra. Açò, amb l'arribada dels primers refugiats a València, principalment de Màlaga i Madrid, entre d'altres ciutats i províncies, feu que es parlara del Levante feliz. Ara bé, què hi havia en realitat d'aquesta suposada felicitat? De la mateixa manera que, a tot l'Estat espanyol, en produir-se l'esdeveniment de la República, i amb l'esclafit de la Guerra d'Espanya, trobem un panorama polític totalment polaritzat, també al País Valencià ens trobem amb unes activitats i agitació polítiques semblants; amb partits tant de dreta com d'esquerra que mobilitzaren un gran nombre de la població, quasi a parts iguals, fent que el clima fora d'allò més tens. Ara bé, resultaria del tot ingenu i irreal considerar que aquesta inestabilitat política, i també social, és fruit únicament dels anys de govern de la República, ja que anà configurant-se durant les tres primeres dècades del segle XX i les darreries del XIX, amb un sistema parlamentari falsejat i una població que demanava cada vegada més una major participació en la vida pública i política.

Paraules clau: Restauració, País Valencià, agitació política, partits polítics, torn pacífic. 


\section{Isabel Clara Eugenia.}

La herencia interrumpida de la Infanta-Gobernadora

Gerardo Ferrer Bartoll al316027@uji.es 
Resumen

Tras diferentes candidatos al matrimonio con Isabel Clara Eugenia desestimados, Felipe II ve como última posibilidad el matrimonio con Alberto de Habsburgo. El interés dinástico condicionará los acuerdos, consecuencias y devenir del matrimonio a su descendencia. La no descendencia del matrimonio consanguíneo efectuado suscitó explicaciones variadas, tanto en la época como en investigaciones posteriores. En algunos casos, podemos concluir que estas derivaciones no estaban suficientemente fundamentadas o justificadas; en otros, encontramos invenciones intencionadas o prejuicios aceptados como verdaderos.

Este trabajo profundiza sobre las diferentes visiones conocidas sobre tal situación a partir de los estudios de especialistas como Duerloo, Parker, Molas o Albaladejo Martínez. Además, sobre la misma fuente primaria de las condiciones del enlace con la documentación que ofrece el Archivo General de Simancas, ofrecemos una interpretación añadida, con una investigación decididamente orientada a visualizar el tratamiento del género en puestos de poder. La desmitificación de prejuicios sobre el tema centra un trabajo con una intencionalidad didáctica de revisión y adaptación a criterios y exigencias para una investigación actual.

Podemos concluir que los roles y desigualdades de género del momento se ensucian con lecturas e interpretaciones desacertadas en cada momento, asociadas al contextos sociales, ideológicos, políticos y mentalidades de diferentes tiempos. Se pondrá de relieve que Isabel Clara Eugenia demostró ser digna para reinar y los argumentos que no lo concibieron de tal modo.

Palabras clave: Isabel Clara Eugenia, Felipe II, Flandes, consanguineidad, sucesión. 


\section{Educació}

Educación

Education Studies 



\section{¿Y si Brandon Stark viviese en nuestro tiempo?}

Una aplicación del Diseño Universal del Aprendizaje en Educación Primaria para activar el rol del alumnado con parálisis cerebral 
Resumen

En el presente trabajo se aplica el Diseño Universal del Aprendizaje (DUA) como método de enseñanza en una clase de 40 de Primaria de la Comunidad Valenciana que tiene un alumno con parálisis cerebral (PC). Los principios del DUA consisten en proporcionar múltiples formas de representación de los contenidos, múltiples formas de implicación y múltiples formas de expresión de aquello que se ha aprendido. El objetivo principal de su aplicación en este trabajo es cambiar el rol del niño con PC de pasivo a activo, potenciando el aprendizaje activo y la solidaridad de todo el alumnado. La meta secundaria es evaluar los valores de inclusión, el conocimiento básico sobre la parálisis cerebral, las expectativas respecto al niño con PC y su autonomía en todo el alumnado, y, por último, el grado de interacción lúdica que se le asocia.

Para lograr esas metas, primero se elabora un marco teórico sobre la parálisis cerebral examinando su origen, prevalencia, definición, causas y problemas asociados. A continuación, se revisa el concepto de discapacidad, diversidad e inclusión, y la legislación al respecto. Posteriormente, la presentación trata los fundamentos neurocientíficos del DUA, las ventajas de los medios digitales para individualizar el aprendizaje y los principios del DUA. Con esa base, se diseña una aplicación, cuya efectividad se evalúa mediante un cuestionario ad hoc simple de 20 ítems pre y post aplicación del DUA

Por último, se evalúan críticamente los objetivos. Primero, se adopta un método vivencial y observacional. El rol del alumno con $P C$ ha pasado de ser pasivo a participativo. A continuación se analizan los resultados de la aplicación metodológica en el aula mediante los cuestionarios, con resultados positivos. No obstante, cabe señalar limitaciones: el muestreo es por conveniencia y no se ha intentado paliar el efecto Rosenthal.

Palabras clave: parálisis cerebral, diseño universal del aprendizaje, inclusión, Educación Primaria. 


\section{Beneficis dels infants bilingües}

en l'adquisició de l'anglés com a tercera llengua

Irene Monzonís Carda

imonzoni@uji.es 
La llengua anglesa comença a introduir-se en el sistema educatiu espanyol des d'edats primerenques, a causa de l'ús de l'anglès com a lingua franca arreu del món. Concretament, a la Comunitat Valenciana, els infants comencen la seva educació amb valencià i castellà com a llengües pròpies de l'entorn i l'anglès com a tercera llengua. Els estudis previs demostren que les persones bilingües tenen més facilitat que els monolingües en l'adquisició de l'anglès com a tercera llengua (L3).

L'objectiu del present treball fou analitzar un grup de 64 preescolars bilingües del CEIP Cervantes-Dualde de Betxí per tal d'establir els possibles avantatges que aquests infants bilingües haurien de tenir en l'adquisició de l'anglès com a tercera llengua. Aquest estudi pretén oferir dades sobre els beneficis del bilingüisme sobre el monolingüisme en l'adquisició de l'anglès com a tercera llengua, de manera que s'invaliden empíricament els biaixos d'una societat bilingüe amb llengües de diferent prestigi, el valencià i el castellà.

Paraules clau: bilingüisme, beneficis, preescolar, tercera llengua, anglès. 


\section{Acurtant distàncies, escoltant de prop}

Paula Fabregat Mas

al297149@uji.es 
Resum

Aquest treball naix de les inquietuds que, com a futura docent, sorgeixen en una alumna de quart del grau d'Educació Infantil. El treball examina l'atenció a la diversitat i la inclusió educativa i desenvolupa una investigació-acció educativa que se centra en un conjunt de propostes que tenen com a objectiu afavorir un ensenyament inclusiu i de qualitat en un xiquet amb discapacitat auditiva. Aquestes propostes s'han portat a terme en l'aula de 5 anys del grup A del CEIP Gaetà Huguet de Castelló de la Plana i han consistit en la realització d'una activitat de ioga i una representació teatral. Pel que fa a la recollida de dades, aquesta s'ha fet amb una observació directa en diferents contextos $i$ amb entrevistes semiestructurades. Les activitats perseguien treballar aspectes com crear un clima inclusiu a l'aula, millorar l'atenció i la concentració per part de l'alumnat o afavorir la participació i la interacció entre totes i tots. Els resultats obtinguts mostren que les activitats proposades han ajudat en gran mesura a aconseguir els objectius plantejats.

Paraules clau: atenció a la diversitat, inclusió, investigació-acció, discapacitat auditiva. 


\section{La orientación en contextos inclusivos:} condicionantes, estrategias, recursos y roles

Erica Lorente Muñoz

lorentee@uji.es 
Resumen

La inclusión educativa es uno de los temas más relevantes dentro del marco de la escuela del siglo XXI, no solo porque su desarrollo responde a criterios de excelencia académica, calidad educativa e igualdad de oportunidades, sino también porque constituye un derecho humano fundamental e inalienable según organismos nacionales e internacionales de elevado prestigio en el ámbito de la educación. No obstante, la inclusión educativa es un reto que, para que sea realmente efectivo, debe impregnar todas las estructuras y colectivos que conforman el centro escolar con el fin de optimar esfuerzos y alcanzar objetivos. Precisamente por eso, este estudio se detiene en la figura de la orientación en los centros educativos de primaria: el psicopedagogo escolar, máximo responsable de la atención de la diversidad, y en su aportación a la escuela inclusiva.

En el presente estudio de caso, de corte cualitativo-inductivo, se analiza el papel de este agente educativo en un Centro Rural Agrupado en constante transformación hacia la escuela inclusiva para determinar qué intervenciones psicopedagógicas facilitan el avance hacia la inclusión y cuáles pueden constituir una barrera. Se trabaja con datos obtenidos a lo largo de dos cursos escolares de diversas fuentes, procesos, técnicas e instrumentos, como son: observaciones participantes, entrevistas, sesiones de empoderamiento al alumnado y de formación al profesorado.

El análisis de los datos muestra una clara tendencia a considerar las condiciones laborales y las percepciones de la comunidad educativa sobre el orientador como unas de las barreras principales para establecer un enfoque psicopedagógico inclusivo de atención a la diversidad. Por otro lado, el proyecto educativo del centro, las estrategias organizativas de aula, y la mirada positiva sobre la diversidad son algunos de los factores que sostienen la inclusión en el centro desde la orientación educativa.

Palabras clave: Inclusión, transformación e intervención psicopedagógica. 


\title{
La filosofía en el aula y la educación para la paz
}

\author{
Un enfoque de pensamiento crítico \\ en la obra plástica El Guernica de Pablo Picasso
}

Ángel Miranda Torres miranda1144@hotmail.com 


\section{Resumen}

La presente investigación tiene por objeto el diseño de una propuesta de carácter filosófico-reflexivo con el objeto de desarrollar capacidades para aprender a pensar bien y a pensar de forma crítica y creativa. La propuesta que se presenta está influida por Lipman, dentro de una corriente de práctica filosófica de tipo pragmático que se ha consolidado para proyectar en la vida cotidiana del profesorado y del alumnado los referentes teóricos relacionados con la realidad educativa. A través del diálogo, se establece lo que Lipman denomina "comunidad de investigación" en el aula. Así, la filosofía en el aula representa un modelo educativo donde las inquietudes de profesorado y alumnado se ven reflejadas con un sentido de participación e involucramiento. Esta idea se aplica al abordaje de cuestionamientos que no dejan de ser representativos, al retomar elementos plásticos de obras que reflejan un análisis puesto a consideración, en este caso, "El Guernica" del autor español Pablo Picasso.

Palabras clave: Guernica; Pablo Picasso; filosofía; paz; educación; Lipman. 


\section{Un programa de intervención en psicología positiva}

para aumentar el bienestar de los docentes

María Luisa García Baldán

baldan@uji.es 
Resumen

El presente proyecto tiene como finalidad analizar la relación entre los niveles de bienestar y la formación en psicología positiva aplicada a la educación, a través de un curso de formación del profesorado de 30 horas de duración, ofertado por el Cefire de Castellón. La hipótesis de la que partimos es que, después de la realización del curso PositivitiEs, se produce un aumento en los niveles de bienestar de los docentes participantes. El objetivo de esta investigación es conocer el impacto que tienen los niveles de bienestar en un grupo de maestros y maestras después de recibir una curso de formación en Psicología Positiva aplicada a la Educación (PositivitiEs), un total de diez sesiones de tres horas cada una, durante un periodo de diez semanas.

Para ello, se midieron los niveles de bienestar antes y después de la realización del curso PositivitiEs. La muestra objeto del presente estudio está compuesta por un total de doce docentes de un centro público de Educación Infantil y Primaria situado en Almassora, un municipio limítrofe a la ciudad de Castelló de la Plana. Se trata de un estudio experimental con dos momentos de medida. Los datos se midieron mediante el cuestionario $\mathrm{PHI}$ y el análisis de datos se realizó con el paquete estadístico SPSS. LoS resultados ponen de manifiesto las diferencias entre los niveles del grupo pre-intervención y el grupo post-intervención. Se detectaron diferencias significativas entre los niveles de bienestar de los participantes antes y después de la realización del curso PositivitiEs: Psicología positiva aplicada a la educación.

Palabras clave: psicología positiva, educación, bienestar. 


\section{Estudio demográfico y factores motivacionales}

de estudiantes con más de 25 años en universidades españolas

Yazmín Monteagudo Cáceres ymonteag@uji.es 
Resumen

Las personas adultas, motivadas por el crecimiento personal, el desarrollo profesional u otras razones, intentan acceder a la enseñanza universitaria u otras enseñanzas más básicas. En este empeño, encuentran diversas dificultades, muchas asociadas a las propias estructuras sociales. El objetivo de la investigación consiste en estudiar los factores motivacionales de estudiantes universitarios con 25 años o más y su demografía. La muestra se obtuvo de universidades españolas públicas, entre las que destacamos la Universidad Complutense de Madrid, la Universidad Nacional de Educación a Distancia y la Universidad de Zaragoza. Se realizó una encuesta online de 15 preguntas cerradas y una abierta entre marzo y julio de 2018, con una participación final de 2361 estudiantes. El procesamiento de los resultados se realizó con el programa SPSS para el estudio descriptivo de la muestra y la pregunta abierta se sometió a un análisis cualitativo.

Los resultados principales relacionan las características sociodemográficas y las principales motivaciones académicas, vinculadas a la mejora de oportunidad de empleo y el gusto personal por el tipo de estudio cursado. Los motivos por los que interrumpieron sus estudios con anterioridad están relacionados con la falta de tiempo por razones de trabajo, familiares y una situación económica desventajosa.

Las conclusiones de este estudio reflejan la situación demográfica actual de los estudiantes que, con más de 25 años, cursan estudios en la enseñanza superior. Otra conclusión importante a destacar son los factores motivacionales que coinciden con la idea de la importancia de la enseñanza adulta vinculada con la práctica y la experiencia personal.

Palabras clave: enseñanza adulta, curso vital, motivación académica. 


\title{
Perspectiva actual de la investigación
}

\author{
en funciones ejecutivas y el rendimiento académico
}

María Mónica Montes Miranda

al365408@uji.es 
Resumen

La neurociencia educativa es un campo de investigación interdisciplinar que busca traducir los resultados de la investigación en neurociencia para comprender los efectos de la educación en el cerebro y mejorar las prácticas de enseñanza-aprendizaje en la escuela. En las últimas dos décadas se ha generado un creciente interés científico en el estudio del desarrollo de las funciones ejecutivas (FE) durante el periodo escolar. La evidencia de que la intervención y entrenamiento de estos procesos puede generar repercusiones positivas en el rendimiento académico (RA) ha estimulado una variada producción de información en los últimos diez años. Este trabajo revisa aquellas investigaciones en las que se vinculan las variables de RA y FE, realizadas entre los años 2000-2018, con el propósito de conocer la perspectiva actual de este campo del conocimiento.

Los resultados muestran un incremento en el interés científico en este campo en los últimos 10 años, con un predominio de estudios experimentales sobre trabajos teóricos. Los hallazgos de estas investigaciones muestran interesantes implicaciones para transformar la educación en las aulas. El aumento de estudios empíricos ha permitido un gran avance en este campo, al ofrecer evidencias de la relación positiva entre RA y $\mathrm{FE}$, y de mejora del rendimiento académico de asignaturas como lenguaje y matemáticas con mejor FE. Sin embargo, la escasez de fundamentación teórica sólida produce imprecisiones en la práctica, que luego se divulgan indiscriminadamente en el ámbito académico y escolar, por lo que, sin la orientación necesaria, pueden ser contraproducentes.

Palabras clave: funciones ejecutivas, rendimiento académico, primaria, neurociencia educativa. 


\section{Aplicación de las ciencias experimentales en nuestro entorno.}

La ruta científica como propuesta didáctica en alumnos de educación secundaria obligatoria

Mireia Adelantado-Renau al117362@uji.es

Gil Lorenzo Valentín valentin@uji.es 
Resumen

El gran impacto de la ciencia en la sociedad actual crea la necesidad de proporcionar una formación científica al alumnado con el fin de fomentar el pensamiento crítico y convertirles en ciudadanos con autonomía para opinar y participar en temas científicos. Estudios previos sugieren que el $53 \%$ del alumnado de 40 curso de Educación Secundaria Obligatoria (ESO) considera las asignaturas de ciencias experimentales no relevantes y de gran dificultad. Por ello se requieren nuevas estrategias docentes que aborden la ciencia desde un punto de vista holístico con el fin de incrementar la motivación y el interés del alumnado. El objetivo principal de este trabajo fue diseñar una ruta científica para favorecer el proceso de enseñanza-aprendizaje en el campo de las ciencias experimentales en alumnos de 4을 curso de ESO. La ruta científica que se presenta consiste en un paseo activo por el Grao de Castellón y se basa principalmente en la metodología mobile learning que consiste en el uso de dispositivos móviles permitiendo un aprendizaje ubicuo. Esta experiencia didáctica se estructura en 5 paradas recorriendo la playa, el pinar y el paseo principal con el fin de trabajar conceptos relacionados con el medio ambiente y la contaminación. Durante dichas paradas, se proponen actividades innovadoras al aire libre relacionadas con la contaminación del agua, del aire, del medio ambiente, la contaminación acústica y el cambio climático. La implementación de metodologías y actividades novedosas de este tipo logra relacionar conceptos teóricos con su contexto real más próximo, lo que podría a su vez favorecer el proceso de enseñanza-aprendizaje al establecer aprendizajes significativos y duraderos.

Palabras clave: ruta científica, ciencias experimentales, propuesta didáctica, contaminación, adolescentes. 


\section{¿Es la inteligencia emocional}

Martín Sánchez Gómez

sanchgom@uji.es

Mireia Adelantado-Renau

adelantm@uji.es

Edgar Bresó Esteve

breso@uji.es 


\section{Resumen}

En los últimos años, la inteligencia emocional (IE) ha adquirido gran importancia en el entorno educativo debido a su relación positiva con el comportamiento y bienestar psicológico en niños y adolescentes. Entre otras cuestiones, numerosos estudios han tratado de analizar las posibles diferencias existentes en la IE en función del sexo, con resultados no concluyentes. Este estudio tiene como objetivo examinar las diferencias en la IE en función del sexo en niños y adolescentes, así como analizar el papel de la inteligencia lógico-matemática en esta relación.

La muestra de esta investigación está compuesta por 380 alumnos (207 chicos y 173 chicas) de educación primaria y secundaria con edades comprendidas entre 9 y 15 años $(11,43 \pm 1,88)$. Los participantes completaron dos cuestionarios: 1) para evaluar la IE (i.e., percepción, comprensión, gestión e IE total) se empleó el cuestionario Mobile Emotional Intelligence Test (MEIT; Sanchez-Gomez y Bresó, 2019) en una versión adaptada a su edad; y 2) para evaluar la inteligencia lógico matemática se utilizó el test de matrices RAVEN en una versión reducida de 12 ítems (Arthur y Day, 1994).

Las niñas presentaron puntuaciones en IE superiores a las de los niños. Sin embargo, los principales hallazgos de este estudio sugieren que no existen diferencias significativas en la IE en función del sexo. Tras ajustar los análisis por la inteligencia lógico-matemática se obtuvieron resultados similares. La IE parece no estar relacionada con el sexo en niños y adolescentes. Se requieren nuevos estudios para clarificar el papel del sexo en la IE en estas poblaciones.

Palabras clave: inteligencia emocional, infancia, adolescencia, inteligencia, género. 
Arthur Jr, Winfred, y David V. Day. 1994. «Development of a short form for the Raven Advanced Progressive Matrices Test». Educational and Psychological measurement 54 (2): 394--403.

Sanchez-Gomez, Martin, y Edgar Breso. 2019. «The Mobile Emotional Intelligence Test (MEIT): An Ability Test to Assess Emotional Intelligence at Work». Sustainability $11(3)$ : 827. doi:10.3390/su11030827 



\section{Estudis Anglesos}

Estudios Ingleses English Studies 



\section{The interpretation of spatial relations}

through a horizontal axis

Nuria Flor Fabregat

al081314@uji.es 
Abstract

The principal aim of this research is to compare the semantics of prepositions by and at to provide an overview of their meaning in context. A corpus of instances of these prepositions in excerpts from the book The Hobbit by Tolkien is regarded. This story is appropriate for the analysis of spatial language because of the relevance of spatial environments and situations in facilitating comprehension of this imaginary world, its senses and movements through objects, animals or characters in a scene. The research focuses on the theoretical notions of frames of reference (Levinson, 2004), image schemas (Johnson, 1987) and the three dimensions of semantic parameters in which the trajector and the landmark are the entities for the construal of a particular scene (Navarro i Ferrando, 2000, 2006; Vandeloise, 1991). The methodology used consists in the contextual analysis of a corpus of examples of each preposition, by and at, and a comparison of the main definitions from two dictionaries (Cambridge dictionary and Oxford dictionary) with the purpose of describing semantic dimensions. Subsequently, the analysis incorporates frames of reference and perceptual dimensions (topology, force-dynamics and function) onto the meanings of these prepositions, which are not usually explained in dictionaries. Finally, as a conclusion, a comparison of these two prepositions -by and at- is displayed for the description of their semantic contrast.

Keywords: by, at, figurative meaning, dimensions of spatial perception, frames of reference. 


\section{References}

Johnson, Mark. 1987. The body in the mind: The bodily basis of meaning, imagination, and reason. Chicago: The University of Chicago Press.

Levinson, Steven C. 2004. Space in Language and Cognition. Explorations in Cognitive Diversity. Cambrdige: Cambridge University Press.

Navarro i Ferrando, Ignasi. 2000. "A Cognitive-Semantic Analysis of the English Lexical Unit In». Cuadernos de Investigación Filológica 26: 189-220.

-. 2006. "On the meaning of three English prepositions». In In roads of Language, Essays in English Studies, edited by Ignasi Navarro and Nieves Alberola, 167-179. Castelló: Publicacions de la Universitat Jaume I.

Vandeloise, Claude. 1991. Spatial Prepositions. A Case Study from French, Chicago: University of Chicago Press.

\section{On-line dictionaries}

https://dictionary.cambridge.org/

https://en.oxforddictionaries.com/english 



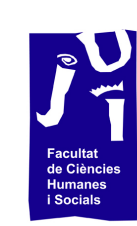

UNIVERSITAT JAUME・I

\section{Scandinavian influence in Old English poetry:}


Abstract

One of the ways in which the general interest on the Viking world has been reflected in academia is the study of the influence that the language of these Northern peoples had in Old English during the Scandinavian invasion (8th-11th century). This paper aims to shed some light on this topic by studying the Scandinavian elements appearing in the Old English poem The Battle of Brunanburh (937). In order to do so, the events involved in the contact between Old English and Old Norse, as well as in the composition of the poem will be contextualised. After this, a review on the nature of The Battle of Brunanburh (i.e. heroic poetry) will be presented together with the proposal of a translation of the poem into contemporary English, with the objective of improving the understanding of the work and thus facilitating its subsequent analysis. Finally, the phenomenon of Scandinavian borrowing in Old English will be introduced, followed by a study of the etymologies of the vocabulary employed in The Battle of Brunanburh. The results of the analysis of the poem's lexicon show that at least 5 out of 343 words in the text are of Scandinvian origin. These findings seem to indicate that, rather than measuring the extent of Scandinavian influence in The Battle of Brunanburh in terms of the quantity of borrowings found in the poem, the influence of Old Norse is better assessed in terms of the nature of these loanwords. Further, factors such as the date and the origin of the poem have also been taken into account for the sake of reaching sensible conclusions.

Keywords: Old English, Old Norse, Scandinavian, loanwords, Brunanburh. 


\section{The effect} of mediated learning experiences on the EFL oral proficiency 
Abstract

Speaking is a language skill that has been deemphasized in the EFL context. With the emergence of sociocultural approaches, the idea of Zone of Proximal Development (ZPD) has recently captured EFL teachers' and researchers' attention. ZPD, as Vygotsky (1978) stated, is "a distance between what a child can do with enough support and assistance of an adult and what he can do individually». Different methods of teaching have ensued - among them, the Dynamic Assessment (DA). There are many DAbased teaching methods that claim to represent ZPD, but none actually does as DA must be based on the 11 attributes of the so-called Mediated Learning Experiences (MLE). The aim of this article is to investigate whether MLE can increase pre-intermediate EFL learners' speaking ability. The study has used a quantitative method of data collection, and a quasiexperimental research methodology, based on a pretest/posttest format with pre-intermediate students $(n=30)$ homogenized through an English speaking proficiency test. Fifteen learners were assigned to the experimental group and the remaining fifteen were assigned to the control group. The learners in the experimental group were taught speaking skills through MLE while the learners in the control group were instructed using a traditional method. All learners participated in 6 two-hour sessions of English speaking class. Then, the teachers administrated the speaking test once more at the end of the course. Finally, the researcher compared and contrasted the changes in the groups through the use of paired sample ttest. The qualitative data were further analysed using content analysis. Results show a significant difference between both groups. MLE allowed learners to speak more fluently while there was no evidence of such a development in the control group. In conclusion, MLE can effectively increase learners' speaking skills. Further research is needed to explore this innovative and influential method of learning, also with other language skills.

Keywords: mediated learning experiences, dynamic assessment, speaking, Zone of Proximal Development, ZPD. 


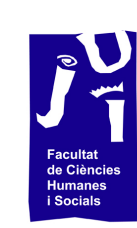

UNIVERSITAT

\section{The new millennial students and the 'multimodal' learning style:}

Podcasting in the ESP classroom

Noelia Gargallo Camarillas ngargall@uji.es 
Abstract

Perceptual learning styles are «the means by which learners extract information from their surroundings through the use of their five senses» (Davis, 2007: 46). Against the background of the technological revolution, the influx of recent learning models available and the emergence of a new generation of students (i.e. millennials), this variable is bound to evolve. Considering that learners perceive the information through different senses, educators should consider their learning preferences and regard the foreign language classroom as a multimodal environment. However, despite the numerous positive results shown by recent studies when matching learning styles and multimodality, research on perceptual learning styles is still limited. The purpose of this study is twofold: (1) to demonstrate the presence of millennial students with a multimodal (rather than multiple) learning style at University and (2) to evince the good results when considering this individual variable in the teaching methodology. The contribution addresses two research questions: (1) is the multimodal learning style present among millennials?, and (2) to what extent a multimodal learning environment contributes to effective learning? Fifty ESP students taking the course Professional English for Communicators at Universitat Jaume I, Spain, were selected as the respondents for this study. A multimodal learning style questionnaire and a podcasting activity were used to obtain relevant data. Results are expected to suggest that millennials are multimodal and that podcasting is an appropriate tool for them to make meaning of their learning environment. These findings may help to identify to what extent technology has affected preferences as to perceptual learning styles.

Keywords: perceptual learning styles, millennials, multimodality, multimodal learning style, ESP, podcasting.

\section{References}

Davis, Sandra E. 2007. «Learning styles and memory». Institute of Learning Style Research Journal 1: 46-51 


\section{Young adult literature and EFL teaching:}

Sherman Alexie's

The Absolutely True Diary of a Part-time Indian (2007)

Elena Dobre

dobre@uji.es 
Abstract

Amalgamating linguistic, affective and cultural elements, the reading of literature in schools acquires a critical role as it not only enables students to meaningfully decipher their reality, but also constitutes a promising tool serving the purpose of linguistic instruction. Nevertheless, the teaching practice of English as a foreign language (henceforth EFL), especially concerning the Spanish secondary education setting, depicts a contradictory scenario. Indeed, research signals that the pedagogical implications and potential benefits of literature - not only in terms of content but as a language teaching resource, are almost systematically overlooked. With this in mind, the aim of this project is to offer an improvement proposal for the current teaching practice of EFL whereby literature is presented as valuable material aiding the purpose of language instruction. To prove so, we describe the implementation of a lesson plan articulated upon a Young Adult literature title, namely Sherman Alexie's The Absolutely True Diary of a Part-Time Indian (2007), designed for a second year of an ESO group (Spanish primary-level instruction). More specifically, following Carter and Long's (1991) triadic model, relevant book fragments have been selected as a means of working upon students' linguistic proficiency, in addition to addressing their cultural and personal growth development. The post-lesson plan conclusion will emphasize students' positive reaction to this classroom experience as a means of signaling that, when delivered in an accessible and attractive format, literature can be relied upon in the language classroom.

Keywords: EFL, YAL, Spanish secondary education, literature, pedagogic innovation. 


\section{Comunicació, Publicitat i Periodisme}

Comunicación, Publicidad y Periodismo Communication Studies, Advertising and Journalism 



\section{Más allá de las noticias falsas.}

\section{Aproximación al fenómeno de la desinformación en línea en el contexto español}




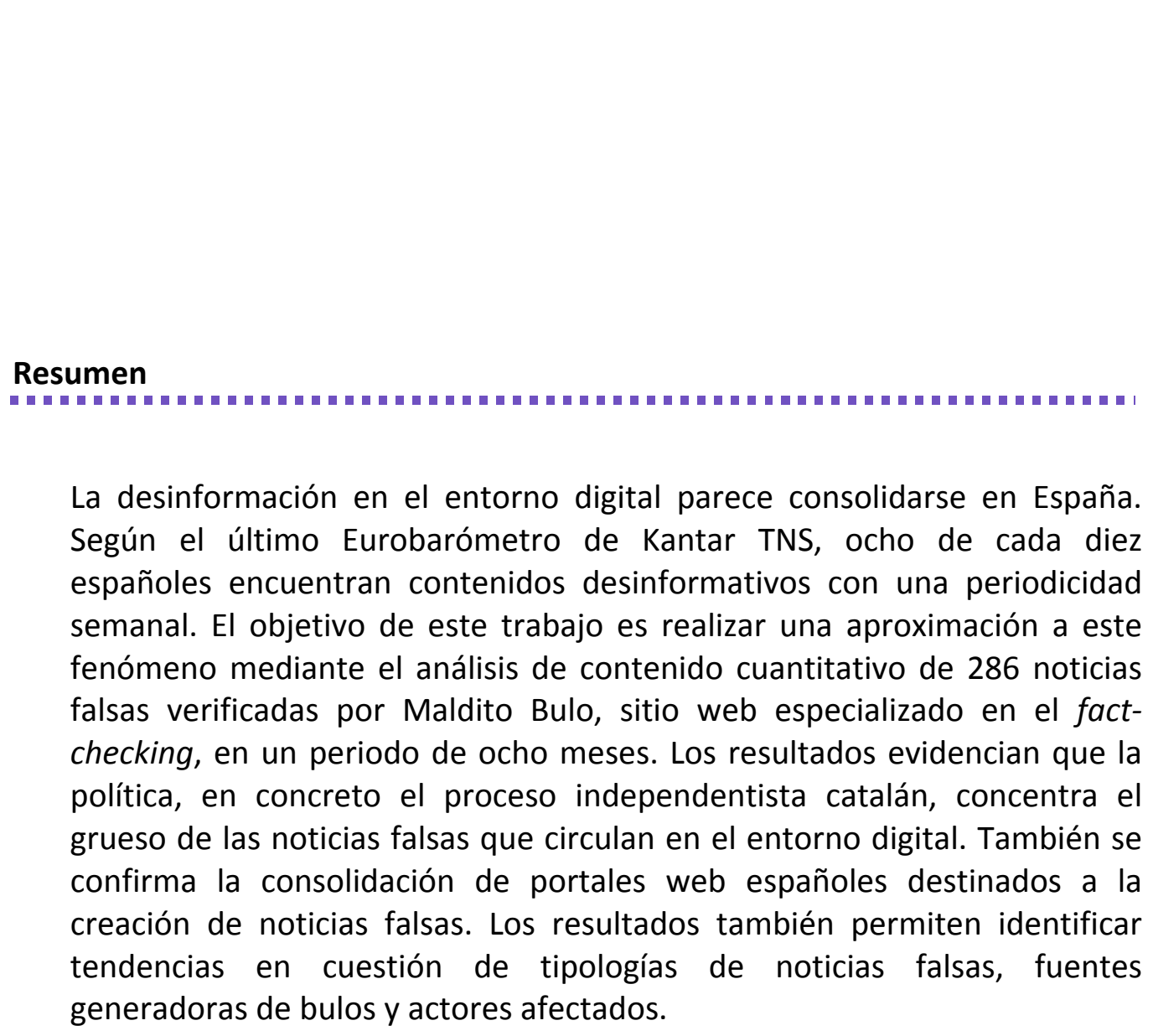

\section{Resumen}

La desinformación en el entorno digital parece consolidarse en España. Según el último Eurobarómetro de Kantar TNS, ocho de cada diez españoles encuentran contenidos desinformativos con una periodicidad semanal. El objetivo de este trabajo es realizar una aproximación a este fenómeno mediante el análisis de contenido cuantitativo de 286 noticias falsas verificadas por Maldito Bulo, sitio web especializado en el factchecking, en un periodo de ocho meses. Los resultados evidencian que la política, en concreto el proceso independentista catalán, concentra el grueso de las noticias falsas que circulan en el entorno digital. También se confirma la consolidación de portales web españoles destinados a la creación de noticias falsas. Los resultados también permiten identificar generadoras de bulos y actores afectados.

Keywords: desinformación, noticias falsas, fake news, posverdad, verificación, fact-checking. 


\section{Influence of celebrity endorsements}

on mature female cosmetic consumers

Leonor Alberola Amores

al390640@uji.es 
Abstract

The aim of this study is to critically investigate how celebrity endorsement influences mature (aged between 40 and 55) female consumers' cosmetic purchasing decisions. It is crucial for cosmetic brands to market their products strategically to reach their intended market and subsequently influence their targets' purchase intent. However, with limited research on mature female consumers, the impact of celebrity endorsement remains unknown: what are the characteristics they deem important in a celebrity cosmetics endorser or what type of celebrity they are more likely to trust and deem credible.

This contribution critically examines the definition of celebrity endorsement and its main features and the theory of consumer behaviour in relation to the influence of celebrity endorsement. The current use of celebrity endorsement in the cosmetics industry will then be discussed. Finally, the results of an online questionnaires (around 100) delivered through Facebook and structured interviews with female consumers aged 40-55 ( $n=10)$ will show that celebrity endorsement it not a major influence for mature female consumers when buying cosmetics. This research reveals that mature female consumers would prefer to see celebrities of similar age who convey that they actually use the endorsed product rather than just appearing with it in an advertisement. Research on a larger sample is required in order to make generalisations on the mature female consumer market.

Keywords: celebrity endorsement, cosmetic, consumer behaviour, marketing, mature female consumer. 


\section{Comunicación de las marcas}

\section{a través del storytelling}

María José Gómez Aguilella aguilelm@uji.es 


\begin{abstract}
El ámbito publicitario cambia y evoluciona con la sociedad. Cada vez más, la tecnología y la personificación subyacen en la comunicación de las marcas. El público objetivo busca mucho más que conocer solo las características de un producto o servicio, por ello hay que acercarse desde la comunicación de intangibles. Para ello, el storytelling comunica los valores de marca a través de historias. El arte se hace presente con la personificación de valores de marca que identifican a ese target, se trata de una posibilidad con una presencia creciente, lo que produce que el interés por prestarle la debida atención para analizarla se incremente también. Este estudio presentará ejemplos de storytelling junto con un marco teórico que ofrecerá los argumentos que destacan su importancia y abrirá la perspectiva sobre posibilidades futuras.
\end{abstract}

Palabras clave: comunicar, intangibles, valores, storytelling, marcas. 


\section{Fashion film:}

\section{definición y tendencias}

Gaspar Molín

gaspar.molin@gmail.com 
Resumen

La necesidad de democratizar la experimentación de las marcas y de superar la barrera del lenguaje en un mercado global ha llevado a los fashion media a adoptar múltiples formas en el metamedio Internet, entre ellas, el fashion film. Esto sucede a raíz de la homogeneización del proceso de producción, que ha llevado a las marcas de moda a recurrir con mayor asiduidad al brand storytelling para añadir valor a sus productos $y$ diferenciarlos. En un nuevo contexto de fuga de audiencias y dobles pantallas, el fashion film toma fuerza dentro de las estrategias de comunicación tanto de grupos empresariales internacionales como de diseñadores noveles locales. Debido a la falta de una definición consensuada desde el ámbito académico, la presente investigación busca definir este término e identificar las tendencias que se dan dentro de este übergenre. Para ello, se ha elaborado una taxonomía propia y se ha realizado un análisis de contenido ad hoc de un corpus de 15 fashion films curados por Marketa Uhlirova para la edición de 2019 del festival Fashion in Film. De estos, se han seleccionado 5 fashion films para ejemplificar la taxonomía creada y las principales tendencias identificadas: editorial en movimiento; simbiosis entre autor y emisor; uso de productos como excusa narrativa: shoppable videos; uso del humor y mostración del fuera de campo y el artificio audiovisual. Este primer acercamiento al término permite comprender el contexto que lo ha generado y explicar las razones de su diversidad, abriendo así camino a una futura investigación más extensa.

Palabras clave: fashion film; comunicación de moda; branded content; brand storytelling; branded entertaintment. 


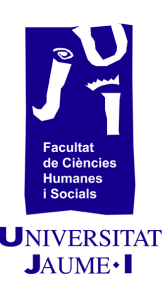

\title{
La cultura maker i la producció d'objectes de forma personal:
}

\author{
nous horitzons per a l'ensenyament, \\ aprenentatge i producció de l'art i el disseny
}

Vicent Juli Iborra Mondéjar vicent.iborra@uji.es 
Resum

Aquesta investigació és un estudi sobre la cultura maker i filosofia DIY (filosofia del fes-t'ho tu mateix, de l'anglès do it yourself). La cultura maker es fonamenta en l'ús de les tecnologies relacionades amb la reproducció i disseny d'objectes I abasta des de la reproducció d'objectes de forma no seriada fins a la producció de videojocs casolans.

El disseny de la recerca ha consistit en la cerca d'informació sobre el tema a Internet i anàlisi de les dades trobades amb l'eina Google Trends. Google Trends és una eina en línia de l'empresa Google que analitza la popularitat de les consultes de cerca al cercador de Google per regions i idiomes. El lloc web utilitza gràfics i compara el volum de cerques de diferents consultes al llarg del temps. L'eina també mostra dades de tendències de cerca.

L'anàlisi de les dades mostra una tendència d'interès generalitzada pel tema entre els anys 2015 i 2017. Com a curiositat, alguns països nòrdics mostren un interès prematur pel tema ja l'any 2005. D'altra banda, les dades també mostren una varietat d'especialitats professionals unides per al disseny d'un mateix producte. Una primera conclusió d'aquesta investigació és el canvi de paradigma en el disseny de productes, on l'usuari passa de ser passiu a ser creador, amb les xarxes socials com a escenari. També s'ha constatat la interacció i col·laboració entre diferents disciplines per al desenvolupament d'eines que permeten millorar l'estudi i producció de tot tipus de disseny. Així mateix, les dades mostren un interès creixent de la ciutadania per l'anomenada revolució digital.

Paraules clau: FabLab, DIY, maker culture, open-source culture. 


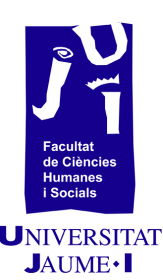

\section{La internacionalización del evento tradicional como potenciador de la marca territorio.}

El caso de las fiestas de la Magdalena de Castelló de la Plana 


\section{Resumen}

La presente comunicación pretende reflejar la importancia de la internacionalización del evento tradicional como potenciador de la marca territorio. En concreto, el artículo se centra en las Fiestas de la Magdalena de Castelló de la Plana. La obtención de este título honorífico a la festividad objeto de estudio el 12 de marzo de 2010 por parte de la Secretaría de Estado del Ministerio de Turismo pone de relevancia la importancia de los valores culturales y de tradición popular de este evento tradicional (patrimonio cultural de un pueblo), pero también el valor intangible formado por los sentimientos, emociones, sensaciones, música, indumentaria y gastronomía que genera. Estas fiestas tradicionales y fundacionales, señal de identidad de un pueblo, que celebra la ciudad de Castelló constituyen un atractivo turístico que es necesario promover a través de la puesta en valor de esta internacionalización que redundará en su economía pero también en su posicionamiento y en la desestacionalización de la demanda. La metodología de este trabajo es el método hipotético deductivo. Se revisan los conceptos de evento tradicional, internacionalización de las fiestas, territorio y marca y se aplican a la investigación y a la repercusión de los mismos.

Palabras clave: evento tradicional, marca territorio, turismo, fiestas de la Magdalena, citimarketing, gestión de eventos. 


\section{Término influencer:}

sesgo entre investigación y estudios sectoriales

Ángela Agulleiro Prats

angelaagulleiro@gmail.com 
Resumen

La investigación sobre fashion influencers en las redes sociales, en general, y en Instagram, en particular, ha cobrado mayor relevancia en los últimos años debido al aumento de las publicaciones de estudios pseudocientíficos y también sectoriales sobre el tema, tanto nacionales como internacionales. Muestra de su creciente relevancia es el auge de las instituciones que aportan información actualizada sobre el perfil y el contexto en torno a los influencers de moda. La mayoría de esa información surge de estudios encargados o realizados por empresas de gestión de influenciadores digitales (Lauchmetrics, 2017, 2018 y 2019; Linqia, 2019; o Socialbikers, 2018); y por organismos independientes (IAB Spain 2018; Adecec, 2016; Augure, 2015; EAE Business School, 2018; o ASA, 2018). Los citados informes se han publicado en paralelo a los artículos científicos que los investigadores realizaban, aportando valor añadido al sector (Sábada y San Miguel, 2014; San Miguel y Sábada, 2017; Pedroni, 2016 y 2015; Rocamora, 2012; Kim et al, 2017; Duffy y Hund, 2015; Audrezet y otros, en prensa; Hearn, 2008; Pino-Romero y CastellóMartínez, 2017; Pérez y Luque, 2017; Fondevilla y otros, 2012; Fernández de Córdoba, 2017; o Clavijo y otros, 2017).

La presente investigación tiene como objetivo compilar, sintetizar y examinar la producción relacionada con los influencers de moda para identificar y/o definir este perfil. Para ello, se analizan los términos y las definiciones identificadas en los estudios sectoriales y científicos publicados durante los últimos cinco años. Los primeros resultados avanzan la falta de unicidad y la existencia de un sesgo terminológico sobre el concepto fashion influencer, reflejando distintas formas de denominar un mismo concepto y la inclusión de nuevos términos como consecuencia del avance y proliferación de las investigaciones y del crecimiento del sector. Como futuras líneas de investigación, nace la necesidad de ahondar en el nacimiento de la marca influencer asociada al influenciador digital de moda y sus subcategorías.

Palabras clave: influencers, influenciadores, investigación, terminología, moda. 
Adecec. 2016. Trabajar con influencers. Fórmulas para una relación eficaz. Recuperado el 5 de noviembre de 2018. http://www.adecec.com/pdf/adecec_presenta_la_guia_"trabajar_con _influencers._formulas_para_una_relacion_eficaz”_.pdf

ASA (Advertising Standards Authority). 2018. Influencer's Guide. Recuperado el 10 de noviembre de 2018. https://www.asa.org.uk/resource/influencers-guide.html

Audrezet, Alice, Gwarlann de Kerviler y Julie Guidry Moulard. En prensa. "Authenticity under threat: When social media influencers need to go beyond self-presentation». Journal of Business Research.

Augure. 2015. Estatus y prácticas de las relaciones con influencers. Recuperado el 20 de noviembre del 2018. https://ipmark.com/wpcontent/uploads/2015/06/Informe-de-las-relaciones-con-Influencers2015-Augure.pdf

Clavijo Ferreira, Lucía, Concha Pérez Curiel, Sergio Luque Ortiz y Marco Pedroni. 2017. "Social Media y Comunicación Corporativa: Nuevo reto en las empresas de Moda». En Del verbo al bit, coordinado por Javier Herrero, 2029-2059. La Laguna: Sociedad Latina de Comunicación Social.

Duffy, Brooke Erin y Emily Hund. 2015. "'Having it All" on Social Media: Entrepreneurial Femininity and Self-Branding Among Fashion Bloggers». Social Media+ Society 1 (2): 1-5.

EAE Business School. 2018. Radiografía del nuevo universo del lujo. Evolución, presente del sector en cifras, protagonistas, consumidores y la vista hacia el futuro. EAE Business School.

Fondevila, Joan Francesc, Josep Lluís del Olmo y Vanesa Bravo. 2012. «Presencia y reputación digital en social media: comparativa en el sector de la moda». Fonseca. Journal of Communication 5: 92-116.

Fernández de Córdoba, Isabel. 2017. Comunicar la moda en internet: medios, marcas, influencias y usuarios. Barcelona: Editorial UOC.

Hearn, Alison. 2008. "Meat, mask, burden: Probing the contours of the branded "self" ». Journal of Consumer Culture 8 (2): 197-217.

IAB Spain. 2018. Estudio anual de redes sociales 2018. Recuperado el 16 de mayo de 2018. https://iabspain.es/wpcontent/uploads/iab_estudioredessociales_2017_vreducida.pdf

Kim, Seungbae, Jinyoung Han, Seunghyun Yoo y Mario Gerla. 2017. «How Are Social Influencers Connected in Instagram?». In International Conference on Social Informatics, editado por Giovanni Luca Ciampaglia, Afra Mashhadi y Taha Yasseri, 257-264. Cham: Springer. 
Launchmetrics. 2017. Informe sobre el estatus sobre el marketing de influencers en 2017. Recuperado el 8 de abril de 2018. https://www.launchmetrics.com/es/recursos/whitepapers/informemarketing-influencers-2017

- 2018. Estatus del marketing de influencers en el sector de la moda, el lujo y la cosmética 2018. Recuperado el 10 de abril de 2018. https://www.launchmetrics.com/es/recursos/blog/marketing-deinfluencers-informe-2018

- 2019. The state of influencer marketing 2019. Special focus on fashion, luxury \& Cosmetics. Recuperado el 5 de mayo de 2019. https://www.launchmetrics.com/landing/influencer-marketing-report2019

Linqia. 2019. The state of Influencer Marketing 2019. Influencer marketing joins the big leagues. Recuperado el 5 de mayo de 2019. https://linqia.com/wp-content/uploads/2019/04/Linqia-State-ofInfluencer-Marketing-2019-Report.pdf

Pedroni, Marco. 2015. " "Stumbling on the heels of my blog": Career, forms of capital, and strategies in the (sub) field of fashion blogging". Fashion Theory 19 (2): 179-199.

- 2016. "Meso-celebrities, fashion and the media: How digital influencers struggle for visibility». Film, Fashion \& Consumption 5 (1): 103-21.

Pérez Curiel, Concha y Sergio Luque Ortiz. 2017. "El marketing de influencia en moda. Estudio del nuevo modelo de consumo en Instagram de los millennials universitarios». AdComunica: Revista Científica de Estrategias, Tendencias e Innovación en Comunicación 15: 255-281.

del Pino Romero, Cristina y Araceli Castelló Martínez. 2017. «La estrategia publicitaria basada en influencers. El caso de SmartGirl by Samsung. Publicidad y Convergencia Mediática». En Nuevas estrategias de comunicación persuasiva, editado por Araceli Castelló-Martínez y Cristina del Pino Romero, 116-146. Sevilla: Egregius.

Rocamora, Agnes. 2012. "Hypertextuality and remediation in the fashion media: The case of fashion blogs». Journalism Practice 6 (1): 92-106.

Sábada, Teresa y Patricia San Miguel. 2014. «Revisión de los Influentials en moda con la aparición de Internet: estudio del caso español a través de stylelovely.com». Revista de Comunicación 13: 60-83.

Sanmiguel, Patricia y Teresa Sábada. 2017. «Nice to be a fashion blogger, hard to be influential: An analysis based on personal characteristics, knowledge criteria, and social factors». Journal of Global Fashion Marketing 9 (1): 40-58. 


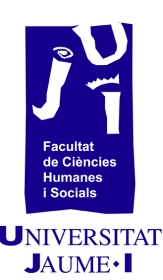

\title{
Propuesta metodológica para el análisis de la relación imagen-texto
}

\author{
en el uso de Instagram \\ como herramienta de comunicación política
}

Alejandra Tirado García

alejandratirado4b@gmail.com 
Resumen

En los últimos años, la red social Instagram se ha convertido en uno de los principales canales que utilizan los actores políticos del panorama internacional e internacional en sus estrategias de comunicación. La red social ha irrumpido con especial empuje en la comunicación política digital dado que permite generar una comunicación natural y cercana con la ciudadanía, en gran parte, por su facilidad de uso a través del móvil. La potencia comunicadora de la imagen digital resulta evidente en una red social como Instagram que surge como un canal de intercambio fotográfico. No obstante, en términos periodísticos y particularmente en su uso como herramienta de comunicación política, la red social se encuentra todavía en una fase de experimentación en busca de sus funciones más eficaces y un estilo comunicativo enmarcado en las prácticas que rige el periodismo profesional.

Este estudio plantea la hipótesis que el uso político de la red social se focaliza en los recursos gráficos, en detrimento, por ende, del aprovechamiento de los recursos textuales que ofrece. Sin embargo, tal y como sucede en el fotoperiodismo tradicional, los datos ofrecidos por los elementos textuales que acompañan a la imagen se convierten en un recurso esencial para su adecuada interpretación, por lo que la correcta gestión del binomio texto-imagen puede convertirse en un factor clave a tener en cuenta en la gestión efectiva de Instagram como herramienta de comunicación política en términos de calidad informativa y legitimidad periodística. Por ello, el trabajo describe la gestión política del binomio imagen-texto en Instagram con una investigación cuantitativa centrada en el estudio de caso de la campaña electoral de las elecciones generales de España de abril 2019. El protocolo de análisis está estructurado en cinco bloques o niveles de estudio y plantea un total de nueve categorías de análisis.

Palabras clave: comunicación política, Instagram, imagen, texto. 